of three miles north-east of the town. The waste of fuel in the form of unburnt coal passing into the atmosphere is represented each year by about 300 tons per square mile in the centre of the town, or, over the whole area of four miles square, about roo tons per square mile. The effect of these suspended impurities in diminishing the amount of sunlight in Leeds may be gathered from the fact that in 1907 the number of hours of bright sunshine was II67 in the town, whilst four miles north-west it reached 1402 hours. The amount of daylight has also been recorded at two different periods by the quantity of iodine liberated from an acid solution of potassium iodide. On the first occasion, over a period of four winter months, it was shown that the smoke in an industrial centre absorbed one-quarter of the daylight as compared with a station one mile to the north-west. In the present investigation, carried out during the month of June of this year, the amount of daylight often fell to one-half in the centre of the town as compared with Garforth several miles away. The relation of soot deposit (black column) to daylight (light column) is shown in the diagram (Fig. 2).

It is the tarry matter in the soot which causes the latter to adlere to and blacken buildings and vegetation. It is sometimes stated that it is the domestic smoke rather than industrial smoke which is injurious to plant life, on

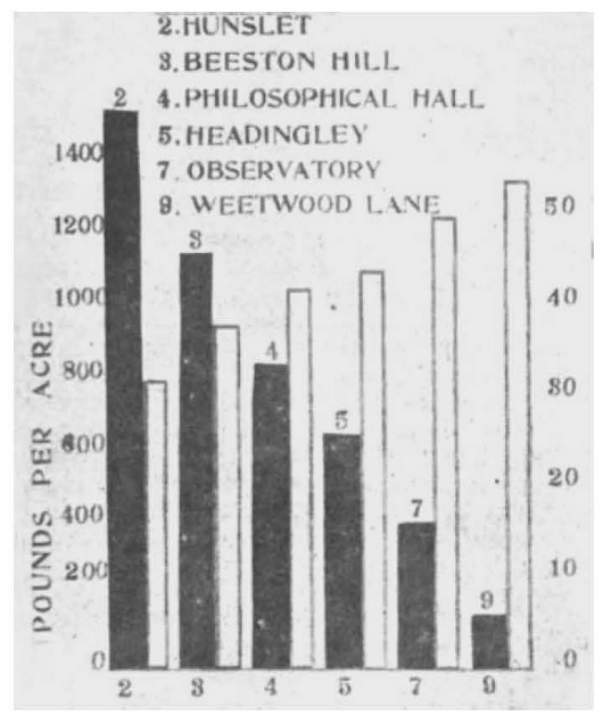

F1G. 2.-Influence of Suspended Matter on Intensity of Light.

account of its higher content of tar. There is a certain justification for this statement, for the percentage of tarry matter in the total solid impurities is highest in the residential and lowest in the industrial areas, varying from is per cent. in the former to 4 per cent. in the latter. When, however, account is taken of the total tarry matter deposited each year, the industrial centres are responsible for the greater quantity, which reaches in some cases ten times the amount in the residential districts. The total culphur, either as sulphurous or sulphuric acid, is everywhere high, but particularly in and near the chief manufacturing areas. A large portion of the free acids is neutralised either by the alkaline fumes of the blast furnaces or by the ammonia of the burnt coal. Still, free acid is present in considerable quantity, and in Hunslet (industrial centre) represents an annual deposit of $90 \mathrm{lb}$. per acre, or $25-30$ tons per square mile.

It is the sulphurous acid which imparts to town fog its choky and irritating effects. The large amount of this acid present in fogs may be gauged from the fact that the hoar-frost collected during the dense fog of January 27 contained acid corresponding to 10.29 parts per 100,000, or more than ten times the average acidity of the same station.

To demonstrate the detrimental effect of sulphuric acid NO. 2085 , VOL. $8 \mathrm{I}]$ upon vegetation, Timothy grass was sown on May 12, 1908 , in boxes $\mathrm{I}$ foot square, the soil being uniform. The seed was watered at a rate corresponding to the average rainfall of 25 inches with water containing different amounts of sulphuric acid. In addition to this, three other samples were watered with Garforth rain water in which the acidity was neutralised, the second with ordinary Garforth rain water, and the third with Leeds rain water. The results were very instructive. In the case of Leeds rain water and of those waters containing a higher degree of acidity, germination was distinctly checked, and the delicate green of the young grass quickly changed to yellow or brown. Grasses watered with water containing 32 parts per 100,000 were killed in a little more than three months, and with 16 parts per 100,000 in less than a year.

Chlorides are found in large quantities, especially in the industrial centres, where, expressed as common salt, they sometimes reach as much as 3 or 4 cwt. per acre, a quantity which must be distinctly prejudicial to vegetation.

The nitrogenous impurities, on the other hand, would be beneficial by acting either as direct stimulants and fertilisers or by neutralising the acidity of the sulphur and chlorine compounds.

\section{MATHEMATICS AND PHYSICS AT THE} BRITISH ASSOCIATION.

THE proceedings of Section A began on Thursday, August 26, with the address of its president, Prof. E. Rutherford, F.R.S., which has already been printed in full in these columns (Nature, August 26, p. 257).

A paper followed, by Prof. J. H. Poynting and $\mathrm{Mr}$. Guy Barlow, on the pressure of radiation against the source. The authors employ thin slips of material which become heated by incident radiation. Those black on both sides experience a pressure equal to the energydensity, $\mathrm{P}$, of the incident radiation; those black on the incident side and brightly silvered on the other experience a pressure I.67 times as great, the excess being due to the radiation which is emitted by one side only of the plate. Plates which are bright both sides experience a pressure $2 \mathrm{P}$, because they do not become heated. Experiments, which are in progress, give good accord with theory. In a short discussion which followed, Prof. Hull intimated that he was alive to the possibility of this reaction when making his experiments on the pressure of incident radiation, but his experiments had been devised carefully so as to prevent its occurrence.

Prof. T. Lyman then gave a summary of the ascertained properties of light of very short wave-lengths ("Schumann rays"), including their ionising and photoelectric effects. To these Prof. Bumstead added that one of his students had shown that the velocity of the electrons emitted photoelectrically increases directly as the frequency of the light up to a wave-length $\lambda=1250-a$ result which Ladenburg had previously shown to hold good for ordinary light.

Prof. Percival Lowell followed with an account of the photographs of Jupiter taken at the Lowell Observatory. The slides exhibited showed a wonderful amount of detail the most noteworthy features being faint wisps that crisscross the several belts, particularly the bright equatorial one. He explained the belts and wisps as gaps in the clouds formed by condensing of uprising vapours from Jupiter's heated interior (he being still a semi-sun), and strung out by his rotation. Prof. Larmor added greatly to the interest of the paper by exhibiting some early drawinss of Tupiter made by Sir W. Huggins, and stated that Sir William's opinion from the first was that the wisps were the edges of cumulus clouds. He noted that the high albedo of Jupiter $\left(7^{2}\right)$ indicates that the Jovian atmosphere acts like a bright cloud; it follows that very little of the mrteorologv of Jupiter can be due to the sun if heat is only absorbed like light. Other planets with a low albedo would have surface markings more like terrestrial ones. The day's proceedings concluded with a paper, by Prof. E. E. Barnard (read by Prof. E. W. Brown) on the motion of some of the small stars in Messier 92 (Herculis). Two of the stars in this cluster are shown to have proper motion; the first (No. II of Schultz's list) is moving awav 
from the centre of the cluster; the second one is moving towards the centre. Several others in the cluster appear to have a slight motion.

On Friday, August 27, owing to the large number of papers presented to the section, it was divided into three departments, which met concurrently. In the mathematical department, Prof. E. H. Moore dealt with fundamental analogies existing in diverse branches of mathematics, and proposed a method for unifying these branches in a more general theory embracing all such analogous branches. Further information with regard to Prof. Moore's theory will be found in a paper by him on a form of general analysis with applications to linear differential and integral equations (Atti del IV. Congresso Internationale dei Mathematici, vol. ii., pp. $\left.9 \delta-I_{14}\right)$, and in a memoir entitled "Introduction to a Form of General Analysis," which will shortly be published by the Yale University Press. Prof. E. H. Hobson, in a paper on the present state of the theory of aggregates, considered a number of points in connection with the theory, and indicated the desirability of a new and more adequate definition of an aggregate of a more restricted character than the one due to $\mathrm{G}$. Cantor, and of such a character that no difficulties would arise from the ascription of a cardinal number to each such aggregate, and also of an ordinal type in case the aggregate is an ordered one. Prof. G. A. Miller, in a paper on generalisations of the icosahedral group, considered the group the two generating operators of which satisfy one of the following three sets of conditions :-

$$
\begin{array}{ll}
t_{1}^{2}=t_{2}{ }^{5}, & \left(t_{1} t_{0}\right)^{3}=\left(t_{2} t_{1}\right)^{3} ; \\
t_{1}^{2}=t_{2}^{3}, & \left(t_{1} t_{2}\right)^{5}=\left(t_{2} t_{1}\right)^{5} ; \\
t_{1}^{3}=t_{2}^{3}, & \left(t_{1} t_{2}\right)^{2}=\left(t_{2} t_{1}\right)^{2} .
\end{array}
$$

Amongst other theorems, Prof. Miller proves the following:- There is an infinite number of groups each of which may be generated by two operators satisfying one of these conditions. Each of the possible groups generated by $t_{1} t_{2}$ contains either the icosahedral group or the group of order 120, which is insoluble and does not contain a subgroup of order 6o, and it must have one of these groups for its commutator subgroup. Prof. G. A. Bliss followed with a new proof of a theorem of Weierstrass concerning the factorisation of power series which states that any convergent series in $p+\mathrm{I}$ variables, $\mathrm{F}\left(x_{1}, x_{2}, x_{3}, \ldots x, y_{n}\right)$ in which the lowest term in $y$ alone is of degree $n$, can be expressed as a product

$$
\left(y^{n}+a_{1} y^{n-1}+\ldots+a_{n-1} y+a_{n}\right) \Phi\left(x_{1} \ldots x_{p}, y\right),
$$

where $a_{1}, a_{2} \ldots a_{n}$ are convergent series in $x_{1}, x_{2} \ldots x_{p}$, which vanish with these arguments, while $\phi$ is a convergent series in all $p+1$ variables with a constant term different from zero. The author also gave formulæ by which the coefficients in the different series may be computed. Mr. J. H. Grace read a paper in which a treatment was given of ideals in a quadratic field, and Prof. W. H. Metzler one on a continuant of order $n+1$ which is expressible as the product of $n+\mathrm{r}$ factors. Prof. Ellery W. Davis gave a complete representation of the elements of the central conic the axes of which are non-similar complex quantities. In a paper on the invention of the slide rule, Prof. F. Cajori sifted the evidence in connection with this subject bearing on the rival claims of Gunter, Oughtred, and Wingate. His conclusion is that the slide rule was undoubtedly invented by William Oughtred in 1832 . Papers by Major P. A. MacMahon on a correspondence in the theory of the partition of numbers, and by Mr. J. W. Nicholson on the asymptotic expansion of Legendre's functions, were read in title only in the absence of the authors. The like fate overtook the report of the committee on the further tabulation of Bessel functions. This committee has made further progress during the year. Using the notation of previous reports, values of $Q_{n}(x)$ have been calculated for integral values of $n$ from $n=\mathrm{x}$ to $n=6$. From these the values of $\sin ^{-1}(Q / R)$ have been computed for the same values of $n$, and the values for $n=\frac{1}{2}, 1 \frac{1}{2}, \ldots 6 \frac{1}{2}$ have been added. From the tables of the present report and those of the I907 report, the values of $J_{n}(x)$ for values of $n$ from o to $6 \frac{1}{2}$ at intervals of $\frac{1}{2}$, and for values of $x$ greater than ro, can be computed to six places without sensible error. The Neumann function $\mathrm{Y}_{n}(x)$ can be calculated from the same data.

NO. 2085 , VOL. $8 \mathrm{r}]$
Meanwhile, the department of general physics was holding a joint meeting with Section $B$ (Chemistry). The papers of more particularly chemical interest will be referred to in the report of the proceedings of that section. Prof. E. Goldstein led off the physical papers with one on the three-fold emission spectra of solid organic compounds, which the council has ordered to be printed in extenso. Prof. Goldstein finds that aromatic substances solidified by liquid air can emit three discontinuous spectra, which are quite different from one another, when they are exposed to kathode rays. First, the initial spectra are observed at the beginning of the luminescence; when these become fainter the chief spectra, which are very characteristic for each substance, appear; the solution spectra are observed when the aromatic substance is dissolved in another medium and the frozen mixture is exposed to kathode rays. All three spectra commence in the red; the initial spectra extend to the ultra-violet; the chief spectra are shorter. Very characteristic solution spectra are given by naphthalene and its derivatives. The solution spectrum varies with the solvent medium. Very small quantities of aromatic bodies are sufficient to give marked solution spectra; on the other hand, the phenomenon gives a very sensitive method of detecting slight impurities. In this way it may be stated that until now no aromatic substance has been prepared in a really pure state. In the consequent discussion Sir J. J. Thomson pointed out that the results would have been clearer if kathodic rays of only one velocity had been employed. Changes come in very abruptly as the energy of the rays passes a certain value. Experiments are in progress in the Cavendish Laboratory upon lithium chloride. With ordinary kathode rays $\left(v=10^{9}\right.$ to $\left.6 \times 10^{9}\right)$ the chloride exhibits a steely-blue appearance, and gives a continuous spectrum; but with positive ions the spectrum shows the lithium red line and very little continuous background. As to the origin of these phosphorescent spectra, he emphasised the fact that phosphorescence is not so much a question of ionisation as of the breaking up of complex aggregates, e.g. iodine vapour phosphoresces without showing any sign of ionisation. You can freeze out the phosphorescence, thereby making these complexes stable. Prof. H. E. Armstrong raised the point as to whether something of the same sort as Goldstein had brought forward goes on in a Welsbach mantle. Experiment shows that you can obtain phosphorescent spectra by inserting traces of rare earths. The next paper was by Mr. E. F. Burton, on the influence of electrolytes on colloidal ferric oxide solutions. A commercial ferric oxide solution was dialysed in conductivity water, and the velocity with which the particles moved in a unit electric field was observed from time to time. As the purification continued the velocity at first increased, but afterwards decreased in almost linear relation with the amount of chlorine found. A comparison of the coagulating powers of monovalent, divalent, and trivalent ions on the colloidal particles indicates that the Linder-PictonHardy law holds good. This paper was followed by one by Dr. Otto Hahn, on methods of separation of radioactive products. These methods are based on the working hypothesis that single radio-active products emit only one type of radiation, either homogeneous $a$ particles or homogeneous $B$ particles. This hypothesis requires that thorium $\mathrm{C}$ and actinium $\mathrm{B}$ be complex. Also, radium $\mathrm{C}$ must be complex, and consist of three products, one emitting $\alpha$ particles and two emitting different $\beta$ particles. Experiments using a "recoil " method seem to support these conclusions. The author also has found that radium itself emits $\beta$ as well as $\alpha$ particles; it also must be complex; and experiment seems to show that the $\beta$ particles come from radium itself, the well-known $a$ particles being due to a new body, radium $\mathrm{X}$. Prof. Rutherford, in commenting upon the paper, pressed the bearing of the results upon the supposed purity of ordinary " chemically pure" bodies. Sir I. Larmor asked for an explanation of the well-known difficulty in connection with the emanation being positively charged after emitting a positively charged body, and in renly Dr. Hahn expressed his belief that $\delta$ particles are simultaneously expelled. In answer to a question of Prof. Bumstead's, Dr. Hahn replied that he had not made any magnetic experiments to test the homogeneity of his various rays. Prof. J. C. McLennan then 
read a paper on the secondary rays excited in different metals by $\alpha$ rays. He finds that the secondary rays emitted by a selected metal when bombarded by the $\alpha$ particles from polonium deposited on copper are proportional to the $\alpha$ radiation, but that different metals are not equally active, the secondary radiation varying from 62 for platinum to 47 for aluminium. $\delta$ radiation excited by polonium appears to be independent of the metal which carries the polonium, and is probably produced by and accompanies the $\alpha$ particle in the course of its expulsion from the polonium atom. Prof. McLennan continued with a paper by Mr. V. E. Pound, on some phenomena associated with the radiations from polonium. By measuring the electrical charge acquired by an insulated metal plate $\mathrm{B}$ placed close to and facing an insulated copper plate A bearing a deposit of polonium, it was made clear with the aid of moderate electric and magnetic fields that there are present (I) $\alpha$ rays emitted by the plate A; (2) an easily absorbed secondary negative radiation emitted by $\mathrm{B}$; and $(3)$ an easily absorbed $\delta$ radiation emitted by $A$. An additional negative stream seemed to arise from the polonium in stronger fields; from its behaviour it is considered to consist of streams of restatoms from the active product RaG or polonium. Dr. O. Reichenheim followed with an important paper, ordered to be printed in extenso, on anode rays and their spectra. $\mathrm{He}$ explained that the conditions for the production of anode rays, or striction-anode rays, are:-(I) the presence of positive ions, produced by heated salts of the alkalis or alkaline earths serving as anode; (2) a high fall of potential at the anode, which is produced by the presence of halogen vapours in the tube, and is the origin of the high velocity acquired by the ions, so that they appear as rays in the tube. A new kind of positive rays passes through a perforated anode under a high gradient of potential. These are called $A_{1}$ rays, because they are analogous to the $\mathrm{K}_{1}$ rays or retrograde rays which leave the kathode. The spectra of anode rays are very simple, often simpler than the arc or spark spectra. The rays show the Doppler effect; in the case of the earth-alkaline rays shifted lines only were found, without any line in the unshifted position. This seems to arise from the fact that we have here to deal with moving particles which emit other lines than the surrounding luminescent gas. A paper by Dr. H. L. Bronson and Mr. A. N. Shaw, on Clark and Weston standard cells, was taken as read owing to lack of time. It dealt with the accuracy and reproducibility of these cells. The mean of five set up in the National Physical Laboratory differs from the mean of the cells set up in Montreal by 5 microvolts. The maximum deviation of their own cells from their mean was only 31 microvolts. The ingredient of main importance is the mercurous sulphate. The ratio of their Weston cells to their Clark cells is 0.716953 as against the value $0.71695^{8}$ determined by Wolff and Waters. Prof. Rutherford concluded with a paper on the action of a rays upon glass, in which he detailed results analogous to the naturally occurring action due to specks of beryl in rock which had been microscopically detected by Prof. Joly.

In the department of cosmical physics, which met simultaneously, Dr. L. A. Bauer gave a résumé of some of the chief results of interest obtained in the magnetic work of the past ten years carried out under his direction by the U.S. Coast and Geodetic Survey and the Carnegie Institute of Washington.

From the detailed magnetic survey of the United States he found that it would not be possible to represent the observed quantities satisfactorily by a general series of spherical harmonics without using a prohibitive number of terms. He found, moreover, by calculating the line integral of the magnetic force around closed circuits, one of which enclosed the whole of the United States, that a part of the magnetic force, $1 / 300$ to $1 / 500$, must be due to non-potential systems, e.g. vertical electric currents. Further calculations to test the existence of such currents are being made with the data obtained by the Carnegie Institute in the Pacific, $1905-8$, and with the recent resumption of the ocean magnetic work by the Carnegie it will soon be possible to make some circuits completely round the earth.

Various types of magnetic disturbances recorded at the NO. 2085, VOL. 8I] five coast and geodetic survey observatories were briefly discussed. An investigation of the relation between solar activity and terrestrial magnetism, carried on in cooperation with Prof. G. E. Hale, showed that the absolute magnetic effect, connected apparently with an increase in solar activity, is equivalent in general to a diminution in the earth's mean intensity of magnetisation. Between February I, 1907, and February I, I908, this amounted to about $\mathrm{I} /$ Ioooth part.

The author emphasised the need in such researches of including all the magnetic elements and of differentiating between effects resulting from internal and external magnetic systems.

Mr. R. F. Stupart read a paper on the distribution of pressure over Canada. He pointed out that the world charts of pressure distribution give an inadequate and even inaccurate representation of the pressure conditions in the dominion. $\mathrm{He}$ found that relatively high pressure in the north-west at Dawson City is accompanied by relatively mild winters, and low pressure by severe winters, a fact which is directly contrary to the prevailing idea that in winter the higher the pressure the lower the temperature over continental areas. Dr. Shaw read a paper, by Mr. J. I. Craig, on the surface motion of air in certain circular storms. The paths of the air in travelling storms were obtained from theoretical considerations, and compared with the paths found by actual observation.

Mr. J. W. Shipley showed photographs of large hailstones observed in western Canada shortly before the meeting. In the centre of one of the stones he discovered a smail fly which had apparently been carried upwards and had formed a nucleus of condensation.

Dr. A. A. Rambaut detailed some of the results of stellar parallax observations carried out at the Radcliffe Observatory, Oxford, with the equatorial instrument acquired about six years ago employing Kapteyn's photographic method. The immediate object of the research was to demonstrate the feasibility of a photographic "Durchmusterung" for parallax extending to stars of the thirteenth and fourteenth magnitude. A paper by Messrs. Plaskett and Harper on two curiously similar spectroscopic binaries concluded the sitting.

On Monday, August 30 , the section met in undivided sessions, which began with a discussion on positive electricity, opened by the president of the association, Sir $\mathrm{J}$. J. Thomson. The questions he asked were:-(I) Is there a definite unit of positive electricity? (2) What is its size? The same negative units are obtainable from both oxygen and hydrogen; is the same true for positive electricity? Attention is concentrated on kanalstrahlen and on the motion of positive ions through mixed gases. Sir Joseph Thomson outlined the evidence afforded by the magnetic and electric behaviour of the kanalstrahlen. $\mathrm{He}$ concludes that the ratio $e / m$ is the same for the positive rays of all gases and vapours (including uranium chloride) at very low pressures, although at high pressures it does depend upon the nature of the gas, and that therefore there is a positive unit of electricity. This is confirmed by Wellisch's experiments on the velocity of the positive ions through mixed gases; their velocity is the same whether they arise from hydrogen or from methyl-iodide. The value of $e / m$ is of the order of $10^{4} ;$ no evidence of smaller particles has been obtained. Some observers, on the other hand. find easily deflected positive rays. It must be remembered that the magnetic field may alter the conditions of the starting of rays, and, secondly, that deflection depends, not only upon $\mathrm{e} / \mathrm{m}$, but also upon the velocity; the easily deflected rays are probably secondary rays. In the discussion which followed many points were raised dealing with side-issues, but the main question did not receive much fresh elucidation, and in the end the predominant feeling was probably that we are still a long way from obtaining as definite experimental knowledge of positive electricity as we at present possess of negative.

Mr. A. S. Eddington next read a paper on the law of distribution of stellar motions, in which he obtains the constants of Schwarzschild's velocity ellipsoid by making use of the mean proper motions of stars instead of the numbers of stars moving in the various directions as the observed data. The following sufficiently exact result is stated. The radius of the velocity ellipse in the direction 
$\theta$ is the geometric mean between the mean P.M. of stars moving in the direction $\theta$ and the mean P.M. of stars moving in the direction $\theta+180$. A paper by Prof. H. T. Barnes dealt with the variation of the specific heat of mercury at high temperatures. Prof. Barnes, employing the continuous-flow method, has now determined the specific heat up to a temperature of $268^{\circ} \mathrm{C}$. with an error (for the higher temperatures) of not more than one or two parts per thousand. The results are specially interesting inasmuch as they show that the specific heat of mercury passes through a minimum at about $140^{\circ} \mathrm{C}$., and then increases fairly rapidly up to the boiling point. The minimum for water occurs at about the same relative position between the freezing and boiling points. During the discussion on the paper Prof. Perry emphasised the great need there is for an accurate determination of the specific heat of superheated steam. Dr. T. Proctor Hall exhibited an apparatus for making enlarged tracings of sound waves from a cylindrical graphophone record, and showed some of the results obtained with it. Prof. A. W. Porter exhibited some transparencies of electric discharges upon photographic plates. A paper by T. Kinoshita was read in his absence by Prof. Rutherford, on the photographic action of a rays, and Prof. A. S. Eve contributed one on secondary radiation by $\gamma$ rays on different metals. Prof. J. C. McLennan then read one by Mr. W. T. Kennedy, on the active deposits from actinium in uniform electric fields. The deposits were obtained on both of two plates $2 \mathrm{~mm}$. apart, under a field of $25^{\circ}$ volts at various atmospheric pressures. As the pressure is decreased from atmospheric the amount of active deposit on both electrodes gradually increases, passes through a maximum value, and then rapidly decreases. The maximum on the kathode is about 2.7 times that for the anode, and is formed at a different pressure. The total deposit is independent of the electric field until potentials bigher than the sparking ones are applied. The coefficients of diffusion of the emanation from actinium into $\mathrm{CO}_{2}$, air, and hydrogen are in the proportion $1 / 1 \cdot 3 / 4 \cdot 2$. On Dr. O. Hahn stating that in the case of actinium emanation it is difficult to know what we are dealing with, the reply was elicited that in all probability a number of products are concerned in the experiments described. A paper by Mr. F. W. Bates, on the effect of "ight on sulphur insulation, was read by Prof. A. S. Eve. The author concludes from some electroscope experiments that sulphur in the presence of light becomes to a slight degree a conductor of electricity to an extent depending upon the intensity of the incident light. In the discussion the resemblance to selenium was pointed out. Dr. Hahn elicited the statement that the effect exhibits no time-lag. Dr. P. Pringsheim mentioned that Röntgen had found a similar effect for paraffin. A paper followed by Dr. T. Franck and Dr. W. Westphal on the charge upon gaseous ions. The authors consider from their experiments that Townsend's doubly charged ions are only a small part of the total ionisation, and that generation in an electric field, contrary to Townsend's view, has nothing to do with their formation. The two kinds can be separated by fractional diffusion if a piece of wire gauze be interposed in their path. The coefficient of diffusion of the double ions is found to be half that of the single ones. With $\alpha, \beta, \gamma$ rays and point discharge no doubly charged ions were found, though in the last case big charged clusters, due to chemical processes, were proved to occur. A paper on the re-combination of ions in air at different temperatures, by Dr. P. Phillips, was read by the recorder. In the experiments outlined in this paper Langevin's method is adopted. The ravs produced by a single discharge in a Röntgen bulb ionise a layer of air between two parallel electrodes, one of which is connected to a Dolezalek electrometer and the other raised to any desired potential. These plates are $3 \mathrm{~cm}$. apart, and the laver of ionised air is $1.5 \mathrm{~cm}$. thick; in these circumstances diffusion is probably negligible. The whole is surrounded by a vapour jacket. The experiment consists in measuring the charges received by the electrometer with different electric fields and temperatures. The following values for $\alpha$, the coefficient of re-combination, were obtained, and are put alongside Prof. Erikson's values recently obtained (Phil. Mag., August) for ions produced by radium :NO. 2085 , VOL. $8 \mathrm{I}]$

\begin{tabular}{|c|c|c|c|c|c|}
\hline \multicolumn{2}{|l|}{ Temperature } & & & & rickson \\
\hline $15^{\circ} \mathrm{C} .$. & $\cdots$ & $1 \cdot 00$ & $\cdots$ & & I.OO \\
\hline 100 & $\ldots$ & 0.50 & $\ldots$ & $\ldots$ & 0.51 \\
\hline 155 & $\cdots$ & 0.40 & $\cdots$ & $\cdots$ & 0.405 (extrapolated) \\
\hline
\end{tabular}

The day's session was concluded with a paper by Prof.John Zeleny and Mr. L. A. McKeehan, on the terminal velocity of fall of small spheres in air. Experimenting with spherical spores, the authors find divergences from Stokes's law for the limiting velocity as follows :-
Substance Radius
Velocity
Theoretical
Lycoperdon
0.000207
Polytricum ... 0.000478
0.04650
$\begin{array}{ll}\ldots & 0.228 \\ \ldots & 1.77\end{array}$
0.417
Lycopodium ... 0.00158
… 3.52

These experiments have an important bearing upon determinations of the numbers of nuclei in cloud condensations. Sir Joseph Larmor attributed the divergences to the inapplicability of the usual theory to particles comparable with the length of the mean free path, and recommended that experiments be made in air of different densities. Prof. Hull agreed that the theory must fail, but expected that the divergences should tend the other way. In answer to Prof. E. W. Brown, it was stated that no Brownian motion or rotation was visible, and the fall was quite steady.

On Tuesday, August $3 \mathrm{x}$, the section began with a discussion on earth tides, opened by Prof. A. E. H. Love. Prof. Love stated that Lord Kelvin had shown (1863) that if the earth could be regarded as homogeneous and absolutely incompressible, and possessed of the same degree of rigidity as steel, the oceanic tides of long period would be reduced, owing to the yielding of the earth, to about twothirds of the theoretical heights which they would have if the substance were absolutely rigid. Sir G. Darwin (I88I) estimated the actual height of the fortnightly tide as about two-thirds the theoretical height. Attempts to measure directly the lunar disturbance of gravity were made by several observers; and recently Dr. O. Hecker, by using two horizontal pendulums mounted in an underground chamber, has demonstrated the existence of the corporeal tide, and has shown that the deflection of such pendulums is about two-thirds what it would be if the earth were absolutely rigid. This means that, besides the tide-raising force, F, of the moon, there act on the pendulum other forces arising from the deformation of the earth. These forces are (I) the component of undisturbed gravity tangential to the deformed surface, denoted by $h \mathrm{~F} ;(2)$ a genuine disturbance of gravity, consisting in the attraction of the tidal protuberances and other related changes of the attraction of the mass of the earth, denoted by $k \mathbf{F}$. The results obtained by Darwin and Hecker, and confirmed by Schweydar, show that the two numbers $h$ and $k$ are connected by the equation $h-k=1 / 3$. To find $h$ and $k$ separately we must have recourse to hypothesis or to new observations. If we adopt Kelvin's hypothesis we find $k=3 h / 5$, and thence $h=5 / 6, k=1 / 2$, and the corresponding estimated height of the corporeal lunar tide is about $46 \mathrm{~cm}$. If, however, we bring in the fact of observation discovered by Dr. S. C. Chandler, viz. that the period of variation of latitude (about ten months if the earth were absolutely rigid) is actually about fourteen months, we can determine $k$ in terms of known quantities. Variations of latitude imply an adjustment of the earth's figure to rotation about an instantaneous axis which does not quite coincide with a principal axis. The corresponding inequality of "centrifugal force" has the same effect as a certain external force producing a deformation of the earth and a genuine disturbance of gravity. If the force in question is denoted by $F$, the genuine disturbance. may be denoted by $k \mathrm{~F}$, where the coefficient $k$ is necessarily the same as in the tidal problem. It has been proved independently by Sir J. Larmor and Prof. Love that $k$. is about $4 / 15$. It thence appears that $h=3 / 5$ approximately, and that the height of the corporeal lunar tide is about $33 \mathrm{~cm}$. The earth would therefore appear to be more rigid than Lord Kelvin estimated it to be, a result confirmed by the interpretation of seismographic records. In the discussion which followed Sir J. Larmor asked whether there was any evidence for Wiechert's theory of the constitution of the earth, viz. 
a central metal nucleus surrounded by a viscous layer and an outer shell of rock. On Clairaut's ellipsoidal theory the internal structure is not determinable from outside effects. Observation of the propagation of earthquakes is a direct experiment on the interior; but even here you cannot go far, because of ignorance of the properties of materials under enormous stresses. The phenomena of terrestrial magnetism are also concerned with the interior. $\mathrm{He}$ asked how the weight of mountain chains is supported. To avoid crushing, the basal material must have the strength of steel. A rival theory is based on the survey of India, viz. that the mass of a mountain is compensated by less dense material underneath; but Burrard's recent researches show that the defect underneath is not nearly so great as was thought. He pointed out that there was room for a fresh calculation. The presence of a mountain chain supported without collapsing necessitates also that the supporting material shall not have any fluidity at all, or else the mountain chains would gradually settle down. $\mathrm{He}$ asked if the necessary calculation had been made. $\mathrm{He}$ pointed out that Hecker's curve, being of the right shape though of the wrong size, was in conflict with a supposition of unequal rigidities in different directions. Finally, he propounded a conundrum of Lord Kelvin's : It is possible for any person in this room, if he lived long enough, to turn the earth upside down! Dr. L. A. Bauer directed attention to the semi-diurnal variation of the earth's magnetism, which has so far not been explained. In reference to Wiechert's theory, Prof. Love stated in reply that if it be adopted the rigidities of the supposed metal nucleus and rocky shell required to satisfy the two conditions $h-k=1 / 3$ and $k=4 / 15$ are respectively about three times and about one-tenth the rigidity of steel. Attention was also directed to the scooped-out beds of the ocean as being much more important than mountains. More than half the surface is 2000 fathoms below the sea-level. The earth is not an ellipsoid; it is the ocean that is so approximately. At the close of the discussion the section again divided.

In the department of general physics two papers were given by Prof. Poynting :-(I) on the lengthening of loaded wires when twisted; (2) the angular momentum in a beam of polarised light. These have appeared in a recent number of the Royal Society Proceedings. Prof. Frank Allen followed, dealing with the effect on the persistence of vision of fatiguing the eye with red, orange, and yellow. The persistence is measured by finding the speed at which flickering ceases when a sectored disc is rotated in front of a source, and a curve is drawn representing the whole spectrum. This persistence is measured when the eye has been fatigued with light of definite wave-length. When fatigued with light of $680 \mu$ and $670 \mu$, only the red part of the curve is affected; fatigued with green only the green part; but when the fatiguing colour lies between $577 \mu$ and $650 \mu$, the curves differ in both red and green. With wave-length $660 \mu$ the two curves coincide completely. This means that the fundamental red sensation is at least beyond wave-length 660 , and that yellow and orange cannot be simple primary sensations. Prof. Allen also contributed a paper on a new method of measuring the luminosity of the spectrum. The principle of the method is that the persistence of a colour sensation is a function of the luminosity only. The next paper was by Profs. E. L. Nichols and E. Merritt, on the effect of low temperature on fluorescence spectra. The measurements consisted in comparing the brightness of the fluorescent spectra of natural willemite, commercial anthracene, an alcoholic solution of fluorescein, and one of resorufin at various temperatures from $20^{\circ} \mathrm{C}$. to $-185^{\circ} \mathrm{C}$., these being excited by a quartz-mercury lamp any portion of the spectrum of which, dispersed through quartz, could be focussed upon the fluorescent body. The results were shown by means of curves. In response to a query by Prof. Rutherford, Prof. Nichols stated that the fluorescent bands tend to hecome narrow as the temperature is diminished. Sir J. Iarmor expressed his opinion that fluorescence was due to molecular creeping, but Prof. Nichols replied that though there is hysteresis (thermoluminescence), his experiments were all conducted slowly so as to eliminate it. A paper on an analogous subject, the absorption and fluorescence of canary glase at low temperatures, was conNo. 2085 , VOL. $8 \mathrm{I}]$ tributed by Mr. R. C. Gibbs. The glass, of known composition, exhibited a main fluorescence band extending from $0.48 \mu$ to $0.59 \mu$. With decreasing temperature the fluorescence for the most part increases, the maximum increase being about 100 per cent. The band, which at ordinary temperature shows a faint indication of two maxima between $0.5 \mathrm{I} \mu$ and $0.535 \mu$, shows at the lowest temperature $\left(-175^{\circ}\right.$ C.) two narrow overlapping bands with maxima at $0.5^{14} \mu$ and $0.533 \mu$.

In the cosmical physics department, which was sitting simultaneously, Prof. W. J. Humphreys communicated some results he had obtained from a consideration of European ballons-sondes observations, while Mr. E. Gold presented the report on the present state of our knowledge of the upper air drawn up by Mr. Harwood and himself. One of the most interesting facts was that both Prof. Humphreys and Mr. Gold found that in areas of high pressure (above $770 \mathrm{~mm}$.) the temperature up to $9-10 \mathrm{~km}$. was greater than in areas of low pressure (below $75^{\circ} \mathrm{mm}$.) while at greater heights the conditions became reversed. So long as this condition holds and the isothermal or advective region exists, it appears impossible that there should be anything in the nature of circulatory interchange between cyclones and anticyclones, and the intensity of these systems cannot be maintained.

Gold and Harwood found remarkable minima in the height at which the advective region begins in March and September, and an attempt was made to connect these minima with the general circulation of the atmosphere.

On Wednesday, September I, the section again bifurcated. In the department of cosnical physics Prof. A. L. Rotch gave an account of the highest balloon ascent in America. He found a remarkable result, which occurred in at least two ascents, that the temperature increased in a cumulus cloud in passing from the base upwards. Considerable discussion took place, and doubt was expressed as to the reality of the phenomenon, but Prof. Rotch stated that the observations were unexceptionable. The fact adds further difficulties to the explanation of cloudformation and its connection with atmospheric motion.

Dr. Shaw showed photographs of models illustrating the temperature distribution in the free atmosphere over the British Isles in the international week in July, roo8. The models show the gradual production or pushing forward of a wedge of cold air at a heirht greater than in $\mathrm{km}$. The wedge had just reached Limerick on the first day, but two days later extended well over England. It may be noted that the construction of the models was only made possible by the observations obtained near Limerick, in Ireland.

Mr. Gold read a paper by Mr. A. Harwood on the results of hourly observations with registering balloons, June $2-3$, 1909. At heights above ro $\mathrm{km}$. there was a diurnal variation of $6^{\circ} \mathrm{C}$. to $8^{\circ} \mathrm{C}$., with the maximum in the middle of the day, but the values were irregularly distributed, and it was impossible to say how far the variations were real or instrumental.

Prof. W. J. Humphrevs described an arrangement for obtaining a record of the ultra-violet part of the solar spectrum (below $0.2 \mu$ ) at very great altitudes.

Mr. Stupart read a paper bv F. Napier Denison on the connection between atmospheric pressure and the motion of the horizontal pendulum of a Milne seismograph.

Simultaneously, in the department of general physics, a paper was given by Mr. R. F. Earhart on the effect of temperature variations on the luminous discharge in gases for low pressures. The potentials were measured which are required to produce, and also those required to maintain, a luminous discharge for pressures varying from $0.2 \mathrm{~mm}$. to $5 \mathrm{~mm}$., and for temperatures from $-78^{\circ} \mathrm{C}$. to $325^{\circ} \mathrm{C}$. Up to $300^{\circ} \mathrm{C}$. Paschen's law holds good for air; for higher temperatures it does not hold even approximately. Prof. Rutherford considered the paper important, because it raises the whole question as to the dependence of ionisation upon temperature. Prof. H. M. MacDonald gave the results of his calculations on the diffraction of electric waves round spherical obstacles. Prof. Love inauired whether the propagation of Marconi waves round the earth could, in the light of these calculations, be attributed simply to the great length of wave employed. Sir J. Larmor reminded the meeting of the 
effect of conduction, which probably played a considerable part in the Marconi system. In Lodge's method the antennæ are not earthed, and the result is that much better resonance is obtained. Prof. MacDonald did not think his results would account for Transatlantic transmission, and pointed out that Lodge's method differed also in the use of shorter wave-lengths and antennæ with a much less distance above the surface. In a paper by Dr. T. H. Havelock, on the instantaneous propagation of a disturbance in a dispersive medium, an attempt was made to remove an apparent anomaly in the results obtained by Lord Rayleigh in a recent paper in the Philosophical Magazine: A paper followed by C. W. Chamberlain, on the relative motion of the earth and æther and the FitzGerald-Lorentz effect. Analysis shows that the total effect of the relative motion is a displacement of the interfering rays in the line of sight, and one at right angles to it. In the interferometer the former should be detected (in the absence of shrinkage); the latter should not. The author suggested an arrangement, called a diffractometer, which he considered should detect the transverse change. Interference is to be produced between two rays travelling at right angles to one another, and the effect will be analysed by a diffraction grating. A change in the length of the path of one of the interfering systems will produce interference bands either in the spectra to the right or to the left. A shift of a whole band is expected for the length of path used in the MorleyMiller experiments and a grating of 30,000 lines to the inch if the apparatus is rotated through ninety degrees. The failure of many experimentalists to find any effect depending upon the earth's motion through the æther has served so much to strengthen the belief of those who hold that it is undetectable that the meeting seemed inclined to receive the proposal with reserve. Prof. Hull pointed out what he considered a flaw in the reasoning. We must therefore await the results of the actual performance of the experiment or a thorough examination of the calculations upon which the belief in its suitability is based. In a somewhat technical paper Prof. E. W. Brown outlined some new methods under trial for tables of the moon's motion. Lieut.-Colonel J. W. Gifford followed with a description of a new cemented triple devised by him for spectroscopic use, the peculiarity being the possession of a ratio of 7.5 of focal length to effective aperture and great freedom from tertiary colour-aberration. Dr. H. G. Dorsey, in an interesting paper on magnetostriction, said that he finds from experiments on eight steel rods of known composition that the maximum elongation due to magnetisation is a function of the carbon content, the curve being similar to a curve in the ironcarbon phase diagram; there is also a relation between it and the maximum susceptibility of a specimen. The maximum retraction bears an inverse relation to Young's modulus. The results tend to straighten out the somewhat chaotic data obtained by other observers. One more paper now remained on the programme, but the inexorable clock pointed out that the time had arrived for the compulsory closing of the sessions. So the final rites were performed, and then an interested group informally examined some remarkable vibration curves of speech exhibited by Prof. D. C. Miller.

\section{CIIEMISTRY AT THE BRITISH ASSOCIATION.}

BEARING in mind the special local conditions attaching to a meeting of the association out of England, the work of the section was organised so as to include the consideration of broad problems of general and local interest rather than the reading of specialised papers. Accordingly, the section sat jointly with the physicists for one session, with the physiologists and agriculturists for another, and with the botanists and agriculturists for a third. These joint discussions were all exceedingly successful and attracted large audiences.

It was regretted that a larger number of the younger English chemists did not make the journey to Canada, and still more that so few of the chemists from eastern Canada were present, though the section was particularly indebted to Mr. F. T. Shutt, of Ottawa, for his contriNO. 2085, VOL. $8 \mathrm{I}$ ] butions to the discussions. The section was strengthened by the presence of a number of American guests, in particular Prof. W. A. Noyes, Prof. G. B. Frankforter, and Dr. A. Springer.

Stress was laid throughout the meeting on the importance and necessity of Winnipeg and the province of Manitoba possessing a university fully up-to-date in every respect. In particular, attention should be devoted in Winnipeg to agricultural chemical research and to the higher training of agriculturists. Wheat must always be a pioneer crop, as it requires less capital, less labour, and less skill than most other types of farming. With fuller development or with some change in the world's requirements a change will come in the farming, and wheat may become a by-product, as often in England now. Such a change comes very quickly, and the farmer will go under unless he is prepared for it and has the highest scientific advice.

In the United States the farmer has realised very definitely the benefits he has obtained by following the results of the experimental stations; in consequence he supports the State universities, and has the greatest belief in the schools. On the western excursion there was abundant opportunity of remarking that the Canadian is equally far-sighted in regard to the schools, but it is none the less necessary to urge that the university work, and above all university research, be not neglected.

Following the president's address, which was delivered at such an hour that members of the section could also attend the addresses delivered by the presidents of Sections $A$ and $G$, the work of the section was opened by a short paper from Prof. W. A. Noyes dealing with his recent work in connection with camphor. A very full report on combustion, by Prof. W. A. Bone, was taken as read. Prof. E. H. Archibald outlined the method followed by him in a new determination of the atomic weight of iridium. Potassium chloroiridate was analysed by weighing the dry salt, reducing it in hydrogen, and estimating the hydrochloric acid formed, the potassium chloride and the metallic iridium set free. The results show a value of 192.9 for the atomic weight. His further paper, contributed jointly with $\mathrm{Mr}$. W. A. Patrick, dealt with the electrical conductivity of solutions of iodine and platinum tetraiodide in ethyl alcohol. The conductivity of solutions of iodine in ethyl alcohol increases rapidly with time, reaching a maximum in about twenty-five hours at $25^{\circ}$ Platinum tetraiodide forms good conducting solutions with alcohol.

A paper of very considerable interest, on the antiputrescent effects of copper salts, in particular towards the bacteria of milk, was contributed by Dr. Alfred Springer. Copper salts are selective in their action, greatly retarding or inhibiting the putrefactive bacteria such as Proteus vulgaris, $P$. mirabilis, $P$. Zenkeri, and Clostridium foetidum, but having little effect on the lactic bacteria. Consequently, milk treated with copper salts retains its sweet odour even when the acidity becomes sufficiently high to curd it. On the other hand, moulds such as Penicillium glaucum, Aspergillus niger, Eurotium repens, and others, grow more freely on milk containing copper salts, probably because they are left a freer field for development. The origin of small traces of copper in the milk supplied by a Cincinnati firm was traced to contamination of the sterilising cloths, pails and other utensils with the boiler compound used to soften the water. Copper salts have an anti-putrescent effect on blood albumen, egg albumen, meat, milk and sewage solutions.

The report of the committee for the study of hydroaromatic substances (secretary, Prof. A. W. Crossley, F.R.S.) describes the preparation of nitro-derivatives of $o$-xylene and the synthesis of isophorone.

The transformation of aromatic nitroamines committee (secretary, Prof. K. J. P. Orton) summarises the results obtained by the study of the transformation of chloroaminobenzene into nitroaniline.

The report of the isomorohous benzene sulphonic acid derivatives committee (secretary, Prof. H. E. Armstrong, F.R.S.) contains the crystallographic data of a number of para-dihalogen derivatives of benzene; these afford confitmation of Barlow and Pope's conclusion as to the existence of columns of carbon spheres in crystalline benzene 